\title{
Comparative study of oral ormeloxifene and levonorgestrel IUCD in management of dysfunctional uterine bleeding
}

\author{
B. S. Dhananjaya ${ }^{1}$, B. Thanmaye ${ }^{2}$, K. Omkara Murthy. ${ }^{3}$ \\ ${ }^{1}$ Dr. B.S. Dhananjaya, Professor and Head, ${ }^{2}$ Dr. B. Thanmaye, Post Graduate, ${ }^{3}$ Dr. K. Omkara Murthy, Professor, \\ Department of Obstetrics and Gynecology, Sri Siddhartha Medical College and Research Center, Tumakuru, Karnataka, \\ India.
}

Corresponding Author: Dr. Thanmaye B, Post Graduate, Department of Obstetrics and Gynecology, Sree Siddhartha Medical College and Research Centre, B.H. Road, Agalakote, Tumkur, Karnataka, India. E-mail: thanmaye21@gmail.com

\begin{abstract}
Introduction: Dysfunctional uterine bleeding constitutes a considerable problem for many women causing discomfort and decreased quality of life. About $10-15 \%$ of women experience episodes of DUB at sometime during the reproductive years of their lives. Annually $5-19 \%$ of women seek medical care. It accounts for more than $25 \%$ of all hysterectomies. A wide range of treatment modalities are available. Objectives: To study efficacy of oral ormeloxifene and levonorgestrel IUCD in terms of blood loss, endometrial thickness, hemoglobin concentration and to evaluate side effects in DUB. Methods: 80 women presenting with dysfunctional uterine bleeding were allocated to 2 equal groups, group1: received $60 \mathrm{mg}$ oral ormeloxifene twice a week for 12 weeks and once a week for next 12 weeks. Group 2: received levonorgestrel IUCD. The primary outcomes were reduction in menstrual blood loss (measured by fall in PBAC score), rise in hemoglobin levels, decrease in endometrial thickness. The follow up was done at $3^{\text {rd }}$ and $6^{\text {th }}$ month. Results: This study shows significant reduction in PBAC scores with use of ormeloxifene $(\mathrm{P}=<0.001)$ and also with Levonorgestrel IUCD $(\mathrm{P}=<0.001)$, hence reduction in blood loss. Significant increase in hemoglobin concentration with ormeloxifene $(\mathrm{P}=<0.001)$ and levonorgestrel IUCD $(\mathrm{P}=0.002)$ and decrease in endometrial thickness with ormeloxifene $(\mathrm{P}=<0.001)$ and levonorgestrel IUCD $(\mathrm{P}=<0.001)$. No statistical significant between the two groups. Conclusion: Both ormeloxifene and levonorgestrel IUCD are equally efficacious and safe. Ormeloxifene is preferred for treatment of DUB as it is easy to administer and cheap compared to levonorgestrel IUCD which is costly and with few side effects like spotting, which makes patient apprehensive.
\end{abstract}

Keywords: Dysfunctional uterine bleeding, Ormeloxifene, levonorgestrel IUCD, PBAC

\section{Introduction}

DUB is a state of abnormal uterine bleeding in the absence of recognizable pelvic pathology, pregnancy or generalized bleeding disorder andmost commonly affects the women of reproductive age [1].

Dysfunctional uterine bleeding constitutes a considerable problem for many women causing discomfort and decreased quality of life. About 10-15\% of women experience episodes of dysfunctional uterine bleeding at some time during the reproductive years of their lives. It is a common cause of iron deficiency anaemia in healthyfemale [2].

Manuscript received: $14^{\text {th }}$ January 2019

Reviewed: $24^{\text {th }}$ January 2019

Author Corrected: $30^{\text {th }}$ January 2019

Accepted for Publication: $5^{\text {th }}$ February 2019
Annually $5-10 \%$ of women of reproductive age seek medical care for DUB which negatively impacts quality of life. Over all it accounts for $6.2 \%$ of genitourinary disease reporting to outpatient department and may account for more than $25 \%$ of all hysterectomies [3].

A wide range of treatment modalities are available for dysfunctional uterine bleeding which include medical therapy and surgical interventions. Pharmacological management can be hormonal or non hormonal. Non hormonal drugs like NSAID'S, ethamsylate and antifibrinolytics have been found to be highly effective. Hormonal agents include progestins, combined OCP's, danazol, GnRH agonists, latest SERMs, oestrogens, sometimes androgens, Levonorgestrel IUCD. RCOG recommends beginning with medical management 


\section{Original Research Article}

before resorting to surgical intervention [3]. Medical management has always been the first therapeutic option to be tried as it is less complicative, less morbidity, and economical. For medical management many drugs are available. Each drug has its own advantages, disadvantages, side effects. Ormeloxifene a non steroidal selective estrogen receptors modulator and has been used for past 20years as an oral contraceptive. It is good option for menorrhagia leading to $77-85 \%$ reduction in menstrual blood loss and causes amenorrhea in $17-42 \%$ patients [1].

Ormeloxifene is a benzopyram SERM, which blocks the cytosol receptors by its competitive binding over estradiol. It is primarily a potent estrogen antagonist and demonstrates a suppressive or a stimulatory effect on gonadotropin release. It normalizes the bleeding from uterine cavity by regularizing the expression of estrogen receptors on the endometrium and hence used in dysfunctional uterine bleeding [3]. It is cheap, effective and has good patient compliance. One minimally invasive procedure for control of menorrhagia is levonorgestrel intrauterine device. The levonorgestrel ICUD has a reservoir containing $52 \mathrm{mg}$ levonorgestrel mixed with polydimethylsiloxane, which controls the rate of hormone release. Menstrual blood loss in women with heavy menstrual bleeding can be reduced by 75 $95 \%$ due to progestin induced decidualization of the endometrium. Levonorgestrel IUCD is an attractive option for ovulatory women with heavy menstrual bleeding.

Hysterectomy should be the last resort in management of dysfunctional uterine bleeding, because of the morbidity, mortality associated with the surgical procedure, economic burden, need for rest.

\section{Materials and Methods}

Setting: The study was conducted in 80 patients (40 into ormeloxifene group and 40 into levonorgestrel group) of reproductive age group attending the outpatient department or admitted in-patients in department of obstetrics and gynecology at Sri Siddhartha Medical College and Research Centre, Tumkur, during the period of November 2016 to April 2018.

Type of study: comparative study.

Inclusion criteria: Women of reproductive age group diagnosed with dysfunctional uterine bleeding.

Exclusion criteria: Patient withpelvic pathology-uterine fibroid, PID, adenomyosis, endometriosis, chronic cervicitis and malignancies of uterus / cervix /ovary / vagina / complex endometrial hyperplasia with atypia and platelet disorders, coagulopathy, previous history of thrombosis,Pregnancy and lactation, PCOS, Hypothyroidism, Chronic cervicitis, Jaundice, hepatic dysfunction, Tb, renal impairment, Hypersensitivity to drug were excluded.

Method: A detailed history, complete physical examination, routine investigations like hemoglobin, bleeding time, clotting time, platelet, RBS, thyroid function tests, liver function test, transvaginal USG to rule out pelvic pathology and to measure endometrial thickness were done to all patients.

The recruitment of the participants to the study groups were done after explaining about the merits and demerits of Ormeloxifene and LNG-IUCD. As by their choices, the subjects were allocated into 2 groups. Group ormeloxifene and Group levonorgestrel IUCD. For group ormeloxifene, the drug ormeloxifene was administered orally in the form of tablet $(60 \mathrm{mg})$ twice a week, for first 12 weeks and then once a week for another 12 weeks and for otherlevonorgestrel intra uterine contraceptive device was inserted. They were advised to attend four weekly or earlier if required to OPD for follow up. Blood hemoglobin levels and endometrial thickness (TVS) were measured initially, at 3 months and at the end of the study (6 months).

A well-designedquestionnaire, recorded the subjective assessment of menstrual flow and dysmenorrhea and/ or any side effects of drugs, pictorial blood loss assessment chart (PBAC) score was recorded.

The main outcome measures will be:

1. Pre-treatment and post treatment assessment of menstrual blood lossobjectively by pictorial blood loss assessment chart (PBAC) scores.

2. Blood haemoglobin levels.

3. Endometrial thickness (trans vaginal scan). 
PBAC scores.

\begin{tabular}{|c|c|c|}
\hline Pads & Lightly soiled & 1 \\
\hline & Moderately soiled & 5 \\
\hline & Saturated & 20 \\
\hline Clots & Small (size of a rupee coin) & 1 \\
\hline & Large (larger than a rupee coin) & 5 \\
\hline
\end{tabular}

Ethical consideration: an informed written consent from all the women who are included in the study was taken with ethical clearance from institute.

Statistical analysis: Descriptive and inferential statistical analysis has been carried out in the present study. Results on continuous measurements are presented on Mean \pm SD (Min-Max) and results on categorical measurements are presented in Number (\%). Significance is assessed at $5 \%$ level of significance. The following assumptions on data is made,

Assumptions: 1. Dependent variables should be normally distributed, 2. Samples drawn from the population should be random, Cases of the samples should be independent Student t test (two tailed, independent) has been used to find the significance of study parameters on continuous scale between two groups (Inter group analysis) on metric parameters. Chi-square/ Fisher Exact test has been used to find the significance of study parameters on categorical scale between two or more groups. Non-parametric setting for Qualitative data analysis. Fisher Exact test used when cell samples are very small.

\section{Results}

Table 1 shows statistics of age distribution, locality and parity of subjects in both ormeloxifene and levonorgestrel IUCD groups.

Table-1: Age, locality, parity distribution of patients studied in ormeloxifene and levonorgestrel IUCD group

\begin{tabular}{|c|c|c|c|c|c|}
\hline Parameters & & Ormeloxifene & LNG IUCD & Total & P value \\
\hline Age $($ Mean \pm SD $)$ & & $38.53 \pm 3.81$ & $40.50 \pm 2.88$ & $39.51 \pm 3.50$ & 0.011 \\
\hline Locality & Urban & $11(27.5 \%)$ & $25(62.5 \%)$ & $36(45 \%)$ & 0.002 \\
\hline & Rural & $29(72.5 \%)$ & $15(37.5 \%)$ & $44(55 \%)$ & \\
\hline Parity & Nulliparous & $0(0 \%)$ & $0(0 \%)$ & $0(0 \%)$ & \\
\hline & Multipara & $40(100 \%)$ & $40(100 \%)$ & $80(100 \%)$ & $<0.001$ \\
\hline
\end{tabular}

$\mathrm{P}=0.011^{*}$, Significant, Student $\mathrm{t}$ test

The mean age of study population in Group Ormeloxifene was $38.53 \pm 3.81$, and in LNG IUCDgroup was 40.50 \pm 2.88 . Majority of women in ormeloxifene group were from rural locality $(72.5 \%)$ and in LNG IUCD group were from urban locality $(62.5 \%)$. All 80 women in both the groups were multiparous.

Table-2: Pictorial blood loss assessment chart score, hemoglobin concentration, endometrial thickness in both the groups.

\begin{tabular}{|c|c|c|c|c|c|}
\hline Parameters & Groups & $\begin{array}{c}\text { Before } \\
\text { treatment }\end{array}$ & $\begin{array}{c}\text { After3 months } \\
\text { treatment }\end{array}$ & $\begin{array}{c}\text { After 6 months } \\
\text { treatment }\end{array}$ & P value \\
\hline PBAC & Ormeloxifene & $174.20 \pm 56.93$ & $22.87 \pm 29.90$ & $3.74 \pm 10.99$ & $<0.001$ \\
\hline & LNG IUCD & $172.08 \pm 41.50$ & $11.76 \pm 22.72$ & $3.97 \pm 10.96$ & $<0.001$ \\
\hline Endometrial thickness & Ormeloxifene & $9.32 \pm 3.10$ & $7.04 \pm 1.67$ & $5.84 \pm 0.99$ & $<0.001$ \\
\hline & LNG IUCD & $10.02 \pm 3.15$ & $6.99 \pm 1.04$ & $5.43 \pm 1.21$ & $<0.001$ \\
\hline Hemoglobin & Ormeloxifene & $10.22 \pm 1.36$ & $10.61 \pm 1.15$ & $11.03 \pm 1.02$ & $<0.001$ \\
\hline & LNG IUCD & $9.78 \pm 1.29$ & $10.14 \pm 1.96$ & $10.64 \pm 1.99$ & 0.002 \\
\hline
\end{tabular}

Student $\mathrm{t}$ test (Two tailed, Independent).PBAC $=$ pictorial blood loss assessment chart, $\mathrm{LNG}=$ Levonorgestrel 


\section{Original Research Article}

Table 2: shows PBAC scores, endometrial thickness, haemoglobin concentration before treatment, 3 months and 6 months after treatment in ormeloxifene and levonorgestrel IUCD groups

PBAC scores is statistically reduced in both ormeloxifene group $(\mathrm{P}=<0.001)$ and LNG IUCD group $(\mathrm{P}=<0.001)$. Table2 shows statistically significant reduction in endometrial thickness after 6 months of treatment in ormeloxifene group $(\mathrm{P}=<0.001)$ and LNG IUCD group $(\mathrm{P}=<0.001)$. Also shows increase in haemoglobin concentration after 6 months of treatment in ormeloxifene group $(\mathrm{P}=<0.001)$ and $\mathrm{LNG}$ IUCD group $(\mathrm{P}=0.002)$.

Table-3: Outcomedistribution in two groups of patients studied.

\begin{tabular}{|c|c|c|c|}
\hline Outcome & Group ormeloxifene & Group LNG IUCD & Total \\
\hline Amenorrhea & $30(75 \%)$ & $32(80 \%)$ & $62(77.5 \%)$ \\
\hline Symptomatically improved & $8(20 \%)$ & $4(10 \%)$ & $12(15 \%)$ \\
\hline Dropout & $0(0 \%)$ & $3(7.5 \%)$ & $3(3.8 \%)$ \\
\hline Hysterectomy & $2(5 \%)$ & $1(2.5 \%)$ & $3(3.8 \%)$ \\
\hline Total & $\mathbf{4 0}(\mathbf{1 0 0} \%)$ & $\mathbf{4 0}(\mathbf{1 0 0} \%)$ & $\mathbf{8 0}(\mathbf{1 0 0} \%)$ \\
\hline
\end{tabular}

$\mathrm{P}=0.185$, Not Significant, Fisher Exact Test

Table 3 shows the outcome of 80 patients (40 in each group) included in the study.Out of 40 patients in group Ormeloxifene, 30 patients attained amenorrhea, 8 patients symptomatically improved, 2 patients underwent hysterectomy. Out of 40 patients in group LNG IUCD, 32 patients attained amenorrhea, 4 patients symptomatically improved, 3 patients lost to follow up, 1 patient underwent hysterectomy.

\section{Discussion}

Medical management has always been the first therapeutic option to be tried and if the results fail, one can resort to surgical interventions. Medical treatment of menorrhagia should aim to relieve symptoms, improve quality of life and to avoid the risk of surgery. The present study was conducted to evaluate the efficacy and safety of oral ormeloxifene and levonorgestrel IUCD in the management of dysfunctional uterine bleeding.

Among 80 patients included in the study, two groups contained 40 patients each. Out of 40 who were treated with oral ormeloxifene, 30 patients attained amenorrhea, 2 patients underwent hysterectomy, 8 patients symptomatically improved. Out of 40 patients treated with levonorgestrel IUCD, 32 patients attained amenorrhea, 1 patient underwent hysterectomy, 4 patients symptomatically improved and 3 patients lost to follow up.

Amenorrhea in our study was defined as absence of bleeding for 3 consecutive cycles.Symptomatically improved patients include patients in whom cycles were 45-60 days but there was significant reduction in bleeding, reduction in PBAC score, reduction in endometrial thickness and increase in hemoglobin percentage.
In this study, the patients who are treated with oral ormeloxifene shows there was significant reduction in menstrual blood loss as assessed by fall in PBAC score (Table2). The mean pretreatment menstrual blood loss (PBAC score) was $174.20 \pm 56.93$ which reduced to $22.87 \pm 29.90$ at 3 months and $3.74 \pm 10.99$ at 6 months with treatment. There was significant reduction in menstrual blood loss in patients with ormeloxifene.

The results of this study (table-2) suggests that the rise in haemoglobin level at the end of 6 months of treatment was $11.03 \pm 1.02$ compared to the pretreatment level of $10.22 \pm 1.36$. The rise in haemoglobin level at the end of 6 months was significant. The mean endometrial thickness (Table-2) in the pretreatment group was $9.32 \pm 3.10$ and there was decrease in mean endometrial thickness at the end of 6 months $5.84 \pm 0.99$ of treatment with oral ormeloxifene.

Dhananjaya et al [4] studied 35 patients with dysfunctional uterine bleeding and found a statistically significant increase in haemoglobin concentration (8.26 to $10.59 \mathrm{~g} / \mathrm{dl}, \mathrm{P}<0.001)$ and statistically significant decrease in endometrial thickness (9.83 to $4.89, \mathrm{P}<$ 0.001 ) after 6 months of treatment with ormeloxifene. Neha et al[5] studied 50 patients and found a PBAC score ranging from $123-643$ pre-treatment and $0-75$ at 


\section{Original Research Article}

the end of 6 month, decrease in endometrial thickness (11.35 to 8.13), rise in haemoglobin level (9.04 to 10.86) after 6 months of treatment with ormeloxifene. In this study, the patients who are treated with levonorgestrel IUCD shows there was significant reduction in menstrual blood loss as assessed by fall in PBAC score (Table2).

The mean pretreatment menstrual blood loss (PBAC score) was $172.08 \pm 41.50$ which reduced to11.76 \pm 22.72 at 3 months and $3.97 \pm 10.96$ at 6 months with treatment. There was significant reduction in menstrual blood loss in patients with levonorgestrel IUCD. The results of this study (table-2) suggests that the rise in haemoglobin level at the end of 6 months of treatment was $10.64 \pm 1.99$ compared to the pretreatment level of $9.78 \pm 1.29$.

The rise in haemoglobin level at the end of 6 months was significant. The mean endometrial thickness (Table-2) in the pretreatment group was $10.02 \pm 3.15$ and there was decrease in mean endometrial thickness at the end of 6 months $5.43 \pm 1.21$ of treatment with levonorgestrel IUCD.

Shalini et al [6] studied 40 patients with dysfunctional uterine bleeding and found a statistically significant increase in haemoglobin concentration (9.84 to $10.06 \mathrm{~g} / \mathrm{dl}$ ) and fall in mean PBAC score of $199.45 \pm 30.23$ before treatment to $53.18 \pm 14.73$ after 6 months of treatment with levonorgesterol IUCD.

Taru G et al [7] studied 70 women with levonorgesterol IUCD insertion for heavy menstrual bleeding which resulted in reduction in menstrual blood loss to $79 \%$ after 6 months of insertion. Improvement in haemoglobin levels from 8.16 to $9.35 \pm 0.7 \mathrm{~g} \%$ by 6 months.

There are no much studies conducted comparing oral ormeloxifene and levonorgestrel IUCD in the management of dysfunctional uterine bleeding.In our study, no major side effects were seen with both oral ormeloxifene and levonorgestrel IUCD. Only 4 patients out of 40 treated with levonorgestrel IUCD had history of spotting pervagina.

In our study both oral ormeloxifene and levonorgestrel IUCD had significant reduction in pictorial blood loss assessment chart score, decrease in endometrial thickness and increase in haemoglobin concentration after treatment for 6 months in patients with dysfunctional uterine bleeding.
Both oral ormeloxifene and levonorgestrel IUCD treatment modalities were safe. Both were efficacious in treatment of dysfunctional uterine bleeding. No statistical significant differences between two treatment modalities were found.

\section{Conclusion}

Heavy menstrual bleeding or dysfunctional uterine bleeding is a very common gynecological problem with wide and varied treatment options with their own merits and demerits. Most of the western guidelines recommend Levonorgestrel IUCD as first line of treatment. From our study we found both Ormeloxifene and Levonorgestrel IUCD are equally efficacious and safe. Ormeloxifene is easy to administer and cheap. Levonorgestrel IUCD is costly but one-time administration with few side effects like spotting, which makes patient apprehensive. Hence Ormeloxifene which is equally effective and cheap can be recommended for the treatment of dysfunctional uterine bleeding.

Scope of the study: No study is available comparing ormeloxifene with levonorgestrel IUCD in management of DUB. Ormeloxifene is cheap, LNG IUCD is costly. From our study both are equally effective.

\section{Contribution by authors}

B S Dhananjaya: conceptualisation, study design and writing the paper, B Thanmaye: carried out the study, collection of data, writing the paper, K Omkaramurthy: analysis.

\section{Funding: Nil, Conflict of interest: Nil \\ Permission from IRB: Yes}

\section{References}

1. Debasmita M, Sumit P, Sima S, Abhijit H, Saroj M, Tapan M, Comparitive study of low dose oral contraceptive pill and ormeloxifene in the treatment of dysfunctional uterine bleeding. International Journal of Health \& Allied Sciences. 2014 Oct-Dec;3(4):225-231.

2. Tariq N, Ayub R, Jaffery T, et al. Efficacy of levonorgestrel intrauterine system (LNG-IUS) for abnormal uterine bleeding and contraception. J Coll Physicians Surg Pak. 2011 Apr;21(4):210-3. doi: 04. 2011/JCPSP.210213.

3. Masand D, Gupta S, Patel J, To Observe Effect of Ormeloxifene in Medical Management of Dysfunctional Uterine Bleeding, J of Evolution of Med and Dent.2015 Jan 12:Vol.4(4):587-597. 


\section{Original Research Article}

4. Bs D, Nanda SK. The role of sevista in the management of dysfunctional uterine bleeding. J Clin Diagn Res. 2013 Jan;7(1):132-4. doi: 10.7860/JCDR/ 2012/4794.2687. Epub 2012 Sep 10.

5. Neha Agarwal, Saroj Singh, Shikha Singh, Mohita Agarwal, Pallavi Manocha. Comparative evaluation of the efficacy and safety of ormeloxifene and norethisterone in dysfunctional uterine bleeding. Int $\mathbf{J}$ Reprod Contracept Obstet Gynecol 2013 Jun; 2(2): 194-198.
6. Shalini Vasudeva, Gunjan Malhotra, SK Gulati, YS Chandel. Mirena and nuvaring in management of dysfunctional uterine bleeding. International Journal of Contemporary Medical Research 2018;5(4):D5-D9.

7. Taru G, Nupur G, Sangeeta G, Pushpa B, Jyoti J, Sushma K. Levonorgestrel Intrauterine System (LNGIUS) in Menorrhagia: A Follow- Up Study, Open Journal of Obstetrics and Gynecology, 2014;4,190-196. http://dx.doi.org/10.4236/ojog.2014.44032.

\section{How to cite this article?}

B. S. Dhananjaya, B. Thanmaye, K. Omkara Murthy. Comparative study of oral ormeloxifene and levonorgestrel IUCD in management of dysfunctional uterine bleeding. Obs Rev:J obstet Gynecol 2019;5(1):13-18.doi:10.17511/joog. 2019.i01.03. 